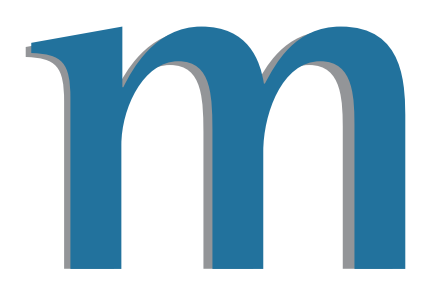

\title{
Um Rosa cor-de-rosa?
}

\author{
David Lopes da Silva \\ Universidade Federal de Alagoas, Brasil \\ http://orcid.org/0000-0003-4766-0252
}

\section{RESUMO}

A partir de coleção de biografemas de Guimarães Rosa - tomado aqui como personagem de seu próprio projeto singularíssimo de cruzamento de vida e obra - o conto "Os chapéus transeuntes" é lido como performance autoficcional; isto é, a escritura dessa estória pode ter servido de gesto de confissão e contrição do próprio Rosa, que assim expiaria seu pecado maior: a Soberba. A hipótese da pesquisa é que existe em vigência no aparato crítico um Rosa cor-de-rosa, tanto no sentido de atenuar sua "fala narcísica" (CHAUVIN, 2020), como no de obliterar a tradicional relação dessa cor à feminilidade. Na conclusão, aventam-se algumas questões sobre o autor talvez ainda não devidamente respondidas.

PALAVRAS-CHAVE: Guimarães Rosa; "Os chapéus transeuntes”; Autoficção; Biografema; Soberba.

\section{A Pink Rosa?}

\section{ABSTRACT}

Departing from a collection of biographemes around João Guimarães Rosa - taken here as a character of his own singular project of intertwining life and work - the short story "Os chapéus transeuntes" will be read as a self-fictional performance; in other words, the writing of this story may have served as a gesture of confession and contrition by Rosa himself, who would thus atone for his greater sin: Pride. My research hypothesis is that the critical apparatus unveils a "pink" Rosa, acting in order to attenuate his "narcissistic speech" (CHAUVIN, 2020), as well as to obliterate the traditional relationship of this color to femininity. As a conclusion, some questions not yet properly answered will be explored about that author.

KEYWORDS: Guimarães Rosa; “Os chapéus transeuntes”; Autofiction; Biographeme; Pride. 


\section{Para Bruno}

Eu sou é eu mesmo.

(Riobaldo)

\section{Introdução}

Em ensaio anterior (SILVA, 2017/2018), constatamos o estranho silêncio da crítica especializada relativo ao conto "Os chapéus transeuntes" (ROSA, 1976 [1964]): de milhares de análises e interpretações sobre a obra rosiana, identificamos apenas cinco autores que se interessaram, e lateralmente, por esse que é o último conto mais longo que Guimarães Rosa publicou em vida. $\mathrm{O}$ artigo mais recente deles também nota a estória como "algo secundarizada" pelo aparato crítico sobre o autor mineiro (MARTÍNEZ PEREIRO, 2017, p. 327). ${ }^{1}$

Lá, procuramos demonstrar a importância dessa estória sobre a Soberba, não somente para o estudo do corpus rosiano, mas para todo o projeto bioficcional do autor, o entrecruzamento de vida e obra, sugerindo como conclusão que até a eleição finalmente vitoriosa para a $\mathrm{ABL}$, em 1963, foi devedora da escritura de OCT. ${ }^{2}$

Prosseguiremos, agora, avançando mais dentro dessa mesma senda, para abrir, na conclusão, algumas questões que, talvez, possam ser tabus ao redor de Rosa - como inclusive o próprio conto OCT -, a fim de edificarem uma imagem cor-de-rosa do autor (isto é, "sem problemas ou falhas", segundo o Dicionário Aulete, mas também bloqueando o que nessa cor remete ao feminino).

Empregando metodologia inspirada na Crítica Biográfica contemporânea, em razão da "possibilidade de reunir teoria e ficção" (SOUZA, 2010, p. 62), provocando um "exercício de ficcionalização da crítica" (SOUZA, 2010, p. 62), visando à construção de "pontes metafóricas entre o fato e a ficção" (SOUZA, 2002, p. 111), intenta-se realizar, através de uma escrita híbrida, "o desempenho performático [que] se caracterizaria por personificar uma constelação de citações de outros discursos, de outros gestos" (AZEVEDO, 2007, p. 85). O ensaio configura-se, assim, como um híbrido de crítica literária e ficção, tornando "híbridas as fronteiras entre o real e o ficcional" (AZEVEDO, 2008, p. 31), e tratando o conto de Rosa como uma performance autoficcional, pois originado de "ideia capaz de superar a dicotomia arte/vida" (KLINGER, 2008, p.19). ${ }^{3}$

\footnotetext{
1 Reconhecemos, no entanto, que a falta de estudos sobre determinado texto é queixa comum entre os pesquisadores. Por exemplo, sobre Corpo de baile, por Sandra Guardini Teixeira Vasconcellos, em Puras misturas (1997); ou Teresa Martins, em 1995, para Tutameia: "ainda é uma obra pouco estudada". (Referências a partir de Frederico Camargo (2017), o qual, no entanto, alerta que, a partir da virada do século, "todos esses livros passaram a receber uma atenção crítica vultosa" (p. 19, nota 16)), o que não podemos dizer de "Os Chapéus Transeuntes" (doravante OCT).

2 A eleição ocorreu em 08/08/1963, para a vaga aberta em 31/03/1963, e o datiloscrito finalizado de OCT (no Instituto de Estudos Brasileiros, da Universidade de São Paulo) leva a data de 21/04/1963.

3 Cf. a ousada hipótese de Marinho (2012, p. 190), que toma até a própria morte de Guimarães Rosa, três dias após a posse na Academia Brasileira de Letras, como "acontecimento performático".
} 
Esperamos, assim, mostrar como o pouco estudado conto "Os chapéus transeuntes" pode filiar-se ao conceito de "autoficção", ${ }^{4}$ mesmo que avant la lettre (o neologismo foi criado em 1977), e ao de performance, cuja arte "supõe uma exposição radical de si mesmo" (KLINGER, 2012 , p. 51), tornando-se assim um daqueles textos escritos com sangue, pelos quais alguém se torna aquilo que é (Nietzsche), pelos quais se pode devir (Deleuze). Com base nesse referencial teórico, pensamos surpreender uma reviravolta no mais íntimo sentimento de Guimarães Rosa, que teria hipoteticamente ocorrido a partir da escritura de OCT, nos primeiros meses de 1963.

\section{Histórico da "autoficção" brasileira}

Os precursores da prática autoficcional no Brasil são já bem conhecidos, graças à crescente onda de estudos sobre o tema na última década: considera-se, normalmente, Lima Barreto como o primeiro cultor do gênero, desde as Recordações do Escrivão Isaías Caminha, e que "quase inscreveu a identidade onomástica [entre autor e personagem] na literatura brasileira em 1919, ao lançar Vida e morte de M.J. Gonzaga de Sá" (HIDALGO, 2013, p. 228-229). A seguir, com o estudo Enigma de Capitu, de Eugênio Gomes (1967) - que aproxima o nome da personagem Capitolina a Carolina, esposa do autor - Machado de Assis torna-se figura central dessa linhagem, ainda mais ao se pensar no Conselheiro Aires, "hipérbole de si [Machado] mesmo", na expressão de Luiz Costa Lima (a partir de OLIVEIRA, 2008). Já no Modernismo, casos claros são os de Graciliano Ramos - para o qual, inclusive, Segato e Leonel (2015, p. 77) elaboram a seguinte tipologia: "autobiografia convencional ou histórica, Infância de 1945; autobiografia de testemunho, Memórias do cárcere de 1953; autobiografia de confissão, Angústia de 1936 e autobiografia de personagem de ficção, São Bernardo de 1934" - e Clarice Lispector: "A hora da estrela corresponde à biografia autoficcional da autora" (FIGUEIREDO, 2016, p. 41). Ou: "Um dos casos mais potentes de autoficção avant la lettre é o de Água viva, de Clarice Lispector" (NASCIMENTO, 2017, p. 617).

E ainda que reconheçamos a reticência contra a postura daqueles que recentemente têm encontrado "autoficção" em obras modernistas, já que o conceito se referiria a "característica própria da narrativa contemporânea" (KLINGER, 2008, p. 18); é a própria Diana Klinger quem infere que tal conceito pode manter, sim, pontos de contato com "narrativas anteriores" (cf. KLINGER, 2008, p. 18). Borowski, embora concorde com a tese de Klinger de que "é possível identificar exemplos que podem ser denominados, retrospectivamente, autoficções avant la lettre" (BOROWSKI, 2017, p. 239), também pede que se guarde o conceito para obras contemporâneas. Mesmo assim, reconhece, em Grande sertão: veredas, "coincidências entre a figura

\footnotetext{
${ }^{4}$ Mesmo que não haja identidade do nome do narrador com o do autor da obra. Em direção diversa, portanto, à de Gama: "nas narrativas rosianas não se efetua um pacto autobiográfico, nem autoficcional, pois não há o autor se apresentando de forma evidente" (GAMA, 2013, p. 219, nota 6). O próprio Rosa, a despeito da declaração famosa de que Grande Sertão: Veredas seria sua "autobiografia irracional” (LORENZ, 1994, p. 58), também diz, paradoxalmente: "sou um dos escritores menos autobiográficos" (CADERNOS, 2006, p. 79). Asserção que se assemelha às de escritores do séc. XXI, como Ricardo Lísias (2015), Daniel Galera (2013) e Clara Averbuck.
} 
do interlocutor intratextual [o doutor da cidade, em visita a Riobaldo] e [o] autor empírico [o próprio Guimarães Rosa]" (BOROWSKI, 2017, p. 242), concluindo que

o silêncio representado na narrativa pelo interlocutor pertence, de uma certa forma, ao domínio da autoficção ou autofabulação, enquanto a fala, em que se cristaliza a presença de Riobaldo, situa-se no universo de ficção autonarrativa. (BOROWSKI, 2017, p. 243). ${ }^{5}$

\section{3. "Os chapéus transeuntes" e a soberba}

$\mathrm{Na}$ história do Ocidente é flagrante que os outros "pecados capitais" foram enormemente aliviados a partir do séc. XX: fala-se de "inveja boa", a proporção sempre crescente de obesos revela o gosto pela glutoneria, a preguiça fora elogiada por Lafargue ainda no século retrasado, o dicionário (Houaiss) remete "avarento" ao previdente "poupador", e mesmo a ira virou até nome de banda de rock. Sobre a luxúria nem é preciso exemplo. Podemos, alegremente, reconhecer em nós qualquer um desses seis pecados; mas o mesmo não se dá com a Soberba. ${ }^{6}$ Ninguém se confessa soberbo. Ligamos a soberba aos males dos nossos tempos, como o egoísmo, o individualismo. Por isso, ressaltamos a coragem de Rosa ao encarar tema tão embaraçoso.

O conto (ROSA, 1976) descreve as últimas horas de vida e o velório e sepultamento de um velho arrogante, através da ótica do neto adolescente Leôncio Nestorzinho, ${ }^{7}$ que, enquanto isso,

\footnotetext{
5 Adotamos a seguinte definição: "autoficção enquanto reinvenção de sua própria vida." (NASCIMENTO, 2017, p. 621). A hipótese deste artigo é que, ao escrever sobre a Soberba, Rosa teria se reinventado, combatendo esse sentimento em si.

6 O parentesco etimológico entre os vocábulos "sobre" e "soberba" (ou a preposição grega "hypér" e o substantivo "hýbris", este também traduzido por "desmesura", "excesso", "insolência", "transgressão", "ultraje") é bem estabelecido, com o aval, inclusive, de Heidegger (1998, p. 334); já o radical latino "hybrid-" possivelmente pertence à mesma família, mas essa derivação não é unânime entre os filólogos. No mundo grego, o conceito de hýbris possui ao menos duas interpretações divergentes, conforme a querela entre Fisher e MacDowell e Dickie (tendemos mais a aceitar a posição destes últimos): "Fisher sees the essence of hybris in 'the committing of acts of intentional insult, of acts which deliberately inflict shame and dishonour on others'. MacDowell, on the other hand, argues that hybris need not involve a victim, and so need not refer to dishonour; its essence, instead, lies in self-indulgent enjoyment of excess energy. Similarly, Dickie argues that hybris is essentially a disposition of over-confidence or presumption, as a result of which one fails to recognize the limitations and precariousness of one's human condition." (CAIRNS, 1996, p. 1). O latim "superbus" é formado a partir da preposição "super", que significa, ao mesmo tempo, "em cima de" e "a respeito de" (FARIA, 1991, p. 529). Vale notar que, assim como "soberbo"/“soberba" são palavras que permitem duas leituras, de valores opostos (como substantivo, corresponde ao indesejável sentimento que guarda relação essencial com a arrogância, a presunção, a imodéstia, a insolência, a vaidade, a vanglória (Houaiss); e, como adjetivo, pode qualificar algo que impressiona por seu caráter grandioso, magnífico, sublime), também a preposição "sobre", analogamente, possui sentido ambivalente, por exemplo quando usada em crítica literária: ao formular que escrevo "sobre Guimarães Rosa", expresso que, de alguma forma, penso situar-me em uma posição "superior" a meu objeto de estudo, ao mesmo tempo em que afirmo que trabalho "com respeito" a ele. Cf., na direção de MacDowell e Dickie, acima: "Como sabemos, o conceito de Übermensch, os trans-homens de Nietzsche, surge moldado já não a uma simples superação dialética mas ao exercício cabal de uma vontade de chance, que não exclui, antes pelo contrário inclui, a experiência hermenêutica. Nesse sentido, toda interpretação, sendo, portanto, interpretação de uma interpretação, exerce algum tipo de violência simbólica sobre outros enunciados prévios. Reorganiza, compacta, suprime, oblitera, preenche, falsifica, enfim, imagina ficções. Ou, em poucas palavras, comete hybris. [...] Nessa linha de análise, caberia mesmo perguntar-se se a hybris do Übermensch não seria, de fato, a pura explosão de uma produtividade imaginária que derramaria sobre todas as coisas uma infinita criatividade de enigmas, vindo a se configurar como a recuperação de uma humanidade autêntica e livre, finalmente, das limitações da metafísica e da moral" (ANTELO, 2009, p. 136).

7 "Nestor", conforme o Dicionário Houaiss, é "homem idoso e de grande sabedoria", o que contrasta com a idade do personagem.
} 
tenta se aproximar da prima $\left(\right.$ Drina $\left.^{8}\right)$ por quem é apaixonado. Resumidamente: Vovô Barão, o "muito chefe da família" (p. 34), está à morte, e seus parentes vêm todos assistir a seu passamento. O nó do problema é que, por despeito a sua falecida esposa, quer ser enterrado no cemitério dos pobres da cidade (e não no outro, o que seria o natural, onde já está Vovó Olegária). Um de seus filhos, Tio Nestornestório (o pai de Drina), de "chapéu rígido em copa" (OCT, p. 39), não quer cumprir o último desejo do moribundo, porque nesse cemitério há uma placa com as “ignóbeis letras" (OCT, p. 45): "VOLTA PARA O PÓ, MÍSERO, AO BARRO DE QUE DEUS TE FEZ" (OCT, p. 59). O desfecho do conto dá-se com o voto vencido dele e o cadáver entrando no cemitério da preferência do Vovô Barão. O impasse, todavia, é resolvido por seu "incaricaturável" (p. 35) criado mudo, o lavador de urinóis Bugubu (também chamado de Ratapulgo), também dominado pela Soberba, que, seguindo sugestão de Drina, passa tinta vermelha na placa, cobrindo a inscrição.

Em artigo anterior (SILVA, 2017/2018), vimos, no entanto, que, no instante de sua morte, Vovô Barão mudou de postura, abandonando a característica deletéria, o que foi percebido pelo neto-narrador, ainda que por um brevíssimo momento. ${ }^{9}$ Tal transformação teria sido percebida também, agora quanto ao escritor Guimarães Rosa, por José Mindlin, que o viu "despojado de toda a vaidade que seus grandes livros pudessem ter lhe posto sobre os ombros" (MINDLIN, 2006, p. 65), nos seus últimos anos de vida, através da leitura dos cartões que Rosa, assinando como "Vovô Joãozinho", enviou a suas netas postiças, entre 1966 e $1967 .{ }^{10}$

Voltando à estória, Vovô Barão é assim descrito, traços esses espalhados pelo conto inteiro, e aqui agrupados: ${ }^{11}$

Teso, obfirmado e assombroso, o muito chefe da família sempre se tivera ausente, qual solitário e irremissivo, ainda que de si dando o que falar, como é destino das torres e dos arrotos sobressair. Supremo no arrogar-se suma primazia, ferrenho em bases e hastes, só aceitava a presença dos parentes

\footnotetext{
8 Drina, de "tez amaciada, maviosa carnação, do rosa com que florescem os pessegueiros e as inglesinhas" (OCT, p. 38). Já sobre o jardim de Vovó Olegaria, descuidado desde sua morte, o narrador diz que conteria, atualmente, "rosas desrosadas em roseiras desfloridas" (OCT, p. 51). Nem o penico do narrador escapa: "bom urinol cor-de-rosa, pintado com gracioso grupo de anjinhos, com ramos de flores em rosa mais vivo, em relevo" (OCT, p. 52). Até o curioso urinol do próprio Vovô Barão, que tinha "pintado, no meio do fundo... um olho!", era "enorme, azul, por fora, azul claro, mas desenhado de flores - rosas, tulipas, florinhas amarelas e vermelhas" (OCT, p. 57). Também o bilhete que Vovó Olegária, "trocista", escreveu para o marido, quando ela estava com laringite, foi "em folha de róseo e perfumado papel de carta" (OCT, p. 50).

9 Ao contrário do Mau Ladrão de Saramago, "rectíssimo homem afinal, a quem sobrou consciência para não fingir acreditar, a coberto de leis divinas e humanas, que um minuto de arrependimento basta para resgatar uma vida inteira de maldade ou uma simples hora de fraqueza" (SARAMAGO, 2005, pág. 10-11). Cf. a passagem da morte do protagonista de OCT, seu "instante verdadeiro": "Vovô Barão afirmou: - 'Eu . . . Eu . . . Eu . . .' - e o mais nada. Devia de ter todos os diabos debaixo da cama. Do que - de que ônus e ranços - não podia ele livrar-se? Se não conseguisse, até ao último dado momento, falhava, talvez definitivamente, estragava-se; seja como se não tivesse sido capaz de repor-se em órbita. E como não o embaraçar? Como ajudá-lo? Senão se o crocodilo pudesse de per si descrocodilar-se... Somenos, pôde. Por um instante verdadeiro, ele sorriu, em menor. Desencurtou o rosto. Para um prodígio de para cima olhar, senhor sim: um olhar - sereno sobre certo sobre justo - que radiasse. De efeito tranquilo, concertado. E não podia ver, e não podia saber, e não podia explicar. Mas só foi o verdadeiro instante. Ocorrera-lhe a grande coisa. Já estava no arroxear-se. Como se fosse dez, derreou-se." (OCT, p. 55. Grifos meus.). 10 Esses cartões, escritos entre 1966 e 1967, foram publicados como Ooó do Vovô: Correspondência de João Guimarães Rosa, Vovô Joãozinho, com Vera e Beatriz Helena Tess (São Paulo: EDUSP, 2003).

11 Foram removidos da citação os colchetes com reticências, marcadores de palavras suprimidas do original, para efeito de legibilidade, restando assim uma espécie de montagem apenas.
} 
quando com solenidade ou chalaça. Estuporava-se todo em intragado e graúdo, e a poesia caíra dele, para sempre, homem pronominal. Fazia questão de história e espaço, mas não tinha copiosidade biográfica. Vivia no tempo das pirâmides. De tão egocêntrico, ele se colecionava. Nem era barão, nunca tendo tido pleno direito ao título, mas assaz permanecia ali - com copo d'água e a colherinha de prata mais a caixa de bicarbonato, de um lado, e do outro a pasta em que guardava os talões de seus pagos impostos, além de, em toda a volta, no chão a pilha relida dos jornais: era um homem de ação, mas com enxaqueca. Ia à igreja, à missa, mas não raro de roupão, de rodaque e chinelos. Calçava sempre botas altas, ou escarpins de saraus, quando não fortes grossas botinas ringidoras, conforme o capricho do humor, assim como entrado em estreito colete, verde ou vermelho ou azul, e de chapéu de forma à cabeça. Todavia, respeitavam-no, até o padre cedia passo, dele aceitavam toda essa destemperatura, e não dava a mão a quase pessoa alguma, na rua não dirigindo palavra a ninguém. Abastado amo-de-si-mesmo, arrogante, ele protagoniza, célebre para si, encegueirado, untado demais de si, homem sem remissão: saudara-nos, entre ironizante e majéstico, sempre com o chicote nas costas, em seus volteios solipsistas. Seus olhos duros como ovos, de muito azeite e pouco pavio, cego para boa parte das coisas, olhos lobislumeantes. O muito faraó sempre parecia visto de muito longe, e, somente, mesmo assim, através de através de uma enfiada de óculos. Torto em ego e excesso. (ROSA, 1976, disperso) $)^{12}$

Sobre Soberba e Humildade, dentre tantas sentenças constantes no conto, o narrador afirma: "aqui rebaixado me revelo, em função de penitente modéstia, num terceiro-ato de humildade" (ROSA, 1976, p. 38), ${ }^{13}$ confissão que remetemos também à pessoa do autor, como possível auto de fé. ${ }^{14}$

\section{Biografemas}

Lançaremos mão, então, de uma prática biografemática, a qual "coloca vida (biografia) e obra (bibliografia) num mesmo plano de contágio" (COSTA, 2010, p. 122). Assim, "[a] vida, ao invés de justificar a obra, é sobreposta a esta mesma obra que se atravessa na própria vida. O Autor da Vida atravessa o Narrador da Obra que, arrebatado por esta paixão, reinventa o Autor da Vida" (COSTA, 2010, p. 122. Grifo meu). ${ }^{15}$

\footnotetext{
12 Calobrezi (2001) e Passos (1988; 2000) leem o personagem Vovô Barão a partir do conceito freudiano de "narcisismo".

${ }_{13}$ Ao contrário do Bugubu, cujos "olhos jamais se rebaixavam" (ROSA, 1976, p. 39). O narrador diz também que, devido ao amor que sente por Drina, "eu me afinava: podia, queria, devia passar a um estado limpamente novo de ser. E não é para isto que é o amor? [...] Súbito, revelava-se-me, imperiosa, arguta, a necessidade de humildade." (OCT, p. 44). E: "um dos secretos objetivos, da ideia da vida, nosso sangue e espírito corrigirem os dos antepassados", querendo, assim, desprender Drina "do traslado de uma árvore genealógica". (OCT, p. 51).

14 Essas correspondências de textos que transitam entre a vida e a obra do autor são largamente estudadas na fortuna crítica sobre Guimarães Rosa. Tome-se, como exemplo, o caso da pedra de Arassuaí, em Grande sertão: veredas: "a pedra de Ara-ssuaí conclui o pacto amoroso entre os personagens Riobaldo e Otacília dentro do romance, da mesma forma que a oferenda do livro (a dedicatória do romance à esposa do autor) - à Ara-cy" (ROSENFIELD, 1993, p. 175).

${ }^{15}$ Embora por vezes arriscando trazer para o nobre campo dos estudos literários, a mera fofoca maledicente.
} 


\subsection{Carlos Heitor Cony em três tempos}

Em entrevista sobre outra coleção produzida em 2000 por encomenda a partir do mesmo tema dos Pecados Capitais (Coleção "Plenos Pecados", da Editora Objetiva), Carlos Heitor Cony relatou o momento da reunião que decidira a distribuição dos pecados pelos autores para o livro de 1964 (do qual Cony fez também parte) em que Guimarães Rosa teria pedido para ficar com o pecado da Soberba:

O Ênio (Silveira) falou: - Eu quero fazer um livro sobre os sete pecados capitais, vocês escolhem os pecados. - Guimarães Rosa escolheu a Soberba, levantou e disse: - Eu quero fazer Soberba. - Aí o Silveira falou assim: - Mas por quê? - Porque eu sou soberbo. - Eu peguei a Luxúria, e foi por aí. Uma obra de encomenda que teve sucesso editorial. (CONY, s/d). ${ }^{16}$

[Misteriosamente, foram removidos da Internet todos os traços dessa entrevista de Cony, que originalmente constava no site da ABL. Apenas Axox (2013, p. 46-48) se refere também a ela, dando outro link do site da ABL, também atualmente fora do ar. Mera coincidência?]

Mais recentemente, o mesmo Cony tece uma avaliação absolutamente em discrepância com o silêncio crítico em torno do conto:

O maior contista da literatura brasileira é o Guimarães Rosa. E o seu melhor conto é "Os chapéus transeuntes", que integra a antologia Sete pecados capitais [sic], uma encomenda do editor Ênio Silveira. O tema é a soberba.

Fui vizinho do Guimarães Rosa no Posto 6, em Copacabana. Guardava o carro na vaga de garagem dele. Era um homem bom, e muito vaidoso. Falava dele próprio na terceira pessoa, pedia que o garoto fosse comprar "o jornal para o Guimarães Rosa". Ou então "o Guimarães Rosa não gosta de samba", como se fosse um personagem. (CONY, 2015, p. 341).

Já para a Folha de São Paulo, Cony foi mais moderado, e, em artigo de 1996, falando sobre a mesma distribuição dos pecados pelos escritores para o livro de 1964, apenas diz: "Rosa ficou com a soberba - e ficou bem" (CONY, 1996). ${ }^{17}$

\subsection{Graciliano Ramos}

Ainda em 1939, no artigo "Um livro inédito", Graciliano Ramos - jurado do "Prêmio Humberto de Campos" (1937) que atribuiu à primeira versão de Sagarana, o segundo lugar no con-

\footnotetext{
${ }_{16}<$ http://www.machadodeassis.org.br/abl/outros/rachel/pales19.htm> (acessado em 14/10/16. Indisponível atualmente na Internet. Grifo meu). Para nós, a própria confissão de Rosa já legitima a leitura de um pacto autoficcional em OCT (assim como as cinco menções a rosas no texto).

17 Cony termina o artigo de dezembro de 1996 revelando: "O José Salomão, da Civilização [Brasileira], já está fazendo os contactos necessários para relançar o livro de 64. É uma boa ideia para movimentar o setor literário." Como sabemos, Os sete pecados capitais foi realmente relançado em 1997, mas com um conto de Fausto Wolff ("O urso e os titãs") no lugar do de Rosa, sem maiores explicações. Não há sequer menção, em toda a Internet, a esse texto de Wolff, quem ganharia o Prêmio Jabuti no mesmo ano em que publicava seu conto no lugar do de Rosa, na segunda edição de Os sete pecados capitais (1997), apesar de o protagonista que encarna a Soberba se chamar Ladislau, em clara alusão a Guimarães Rosa, que "pelo gosto paterno, se chamaria Ladislau. Mas prevaleceu o João, em honra de São João, que nascera três dias antes" (ROSA, V., 2008, p. 395). Cf. Silva (2011) sobre a presença do nome Ladislau em várias obras de Rosa.
} 
curso -, incomodado com o não aparecimento do autor do livro de contos - que teria direito, inclusive, por decisão do júri, a ter seu livro publicado pela Editora José Olympio -, acerta na mosca (azul) ao desabafar sobre o sumiço de "Viator", que se valeu do pseudônimo para preservar-se oculto: "esse silêncio não é razoável", "parece que esse homem não se contenta com o segundo lugar", questionando afinal se seria "orgulho ou modéstia?" o que o impedia de entrar em contato com os realizadores do certame (RAMOS, 2002, p. 148-149. Grifo meu.) $)^{18}$

\subsection{Luiz Otávio Savassi Rocha}

Luiz Otávio Savassi Rocha, a partir de anotações contidas em um dos famosos cadernos de Rosa, analisa que ele seria

uma pessoa demasiadamente preocupada com a própria imagem, com o alheio julgamento; ${ }^{19} \mathrm{en}-$ fim, um inseguro no qual muitos viam um grande vaidoso, por paradoxal que à primeira vista possa parecer. [...] "Cordialíssimo" - escreve a seu respeito um de seus raros amigos íntimos - Franklin de Oliveira (ROCHA, 1981, p. 30-31). ${ }^{20}$

\subsection{Vilma Guimarães Rosa}

Em sentido francamente contrário, nos seus Relembramentos, a filha do romancista - que não utiliza nenhuma vez, no livro, a palavra "soberba", e apenas cita o título do conto OCT uma única vez, sem nenhuma explicação de seu assunto (ROSA, V., 2008, p. 116) - atribui, no círculo familiar, "orgulho" 21 apenas a quem tem esse sentimento por outra pessoa: "[GR] se orgulhava dos netos" (p. 62); "Sempre ganhei o primeiro exemplar de seus livros [de JGR], e isto me envaidecia, orgulhando-me de suas belas dedicatórias" (p. 58); "ela [a mãe, Lygia, primeira esposa de JGR] sempre me dizia, com orgulho, que meu primeiro banho foram as lágrimas dele enquanto me segurava, emocionado” (p. 43); “[GR] Muito se orgulhava em desenvolver a inspiração com as informações que o pai lhe transmitia" (p. 38).

\footnotetext{
18 Sobre diferenças entre Sezão e Sagarana, a partir de análise comparativa das duas versões do conto "Conversa de bois", cf. MARINHO e SILVA, 2019a.

19 A Paulo Dantas, Rosa teria dito: "Sou humano. Preocupa-me o alheio julgamento." (DANTAS, 1975, p. 42).

20 Sugestivo Rosa ser descrito como "cordialíssimo": em Silva e Vilar (2017), elencamos a presença de diversas referências ao "coração" no discurso de posse na ABL "O verbo \& o logos", de 1967, tais como a insistência no nome de sua cidade natal (Cordisburgo), a afirmação que seu antecessor João Neves da Fontoura também possuía grande coração (há recorrentes truques no Discurso com a intenção de identificar seu "xará" e amigo a si mesmo, para, assim, poder falar de si enquanto fala do outro, hábito comum do autor), até as diversas menções a Getúlio Vargas, que se suicidou com um tiro no coração (cf. MARINHO, 2012, p. 187) e a referência ao ex-presidente da República Arthur Bernardes, que sofrera morte súbita devido a infarto do miocárdio. "Senha ou casualidade?" (ROSA, 2008, p. 566), pergunta-se em dado momento Rosa, que, como sabemos, viria a morrer apenas três dias depois de proferir o Discurso. Cf. a descrição de Rosa por seu primeiro entrevistador, em 1946: "[Rosa era] Um rapaz gordo, cordial e míope" (José Cesar Borba, "Histórias de Itaguara e Cordisburgo", citado a partir de VIANNA, 2019, p. 137. Disponível em <http://memoria.bn.br/DocReader/089842_05/31337>).

${ }^{21}$ Sobre a diferença entre "orgulho" e "soberba", cf.: "O orgulho nem sempre se dá a conhecer e, algumas vezes, se disfarça com a máscara da humildade; e a soberba não se esconde, nem se peja de ostentar seu art entonado e desdenhoso." (SANT'ANNA, 2001, p. 136).
} 


\subsection{Fernando Camacho}

Por outro lado, conta Fernando Camacho, ao introduzir sua entrevista com Rosa, o que teria ouvido de um terceiro, também em contradição com a imagem do vice-cônsul que se colocara em perigo para salvar judeus na Alemanha nazista: "Uma pessoa que nos desconhecia a ambos disse-me que Rosa era extremamente egoísta, incapaz de ajudar a ninguém..." (CAMACHO, 1966)..$^{22}$

\subsection{Vilém Flusser}

"Nos diálogos com Rosa havia um único tema: Rosa. [...] é preciso confessar que o autocentrismo de Rosa exigia grande esforço de autodenegação - tarefa difícil, dada a própria tendência para se tomar por centro do universo". 23

"Com efeito: tal livro [Língua e realidade, de Flusser] era o constante pretexto dos diálogos com Rosa: falava-se aparentemente no livro, quando na realidade se falava sempre em Rosa" (FLUSSER, 2007, p. 136). ${ }^{24}$

\subsection{Alaor Barbosa}

Durante os nossos diálogos, ele nada ficou sabendo - eis um exemplo - sobre minha família: meus pais, meus irmãos, minha gente. [...] Nunca me indagou sobre meus projetos de vida e mesmo de criação literária. Nunca me perguntou se eu estava escrevendo ou que livros eu andava lendo (Ele pouco falou comigo de livros e de escritores). Quanto a leitura de livros, aliás, as únicas perguntas que eu ouvi dele foram nesses termos: "Você tem lido Guimarães Rosa?" "Sente-se aqui e me diga se você tem lido João Guimarães Rosa!” Eu lhe julgava a vaidade natural, meio infantil, meio brincalhona, como se ele estivesse mais posando de vaidoso do que sendo vaidoso: como se ele estivesse mais representando do que sendo. (BARBOSA, 2007, p. 28-29)

\subsection{Paulo Dantas}

Outra tarde cheguei ao Itamarati e sua sala, das nossas falas, estava vazia. Rosa, feito um beato manso, carregando uma imensa cruz, pervagava pelos corredores. Cantava, debulhando um imenso terço pardo. Estava completamente fora de si. Chorava e rezava. Cheio de humildade e pena de si mesmo. [...]

\footnotetext{
22 Já Walmir Ayala, em artigo publicado no Correio da Manhã alguns dias após a morte do romancista, explica que o egoísmo atribuído a ele, era apenas "cuidado consigo mesmo" (AYALA, 1967) Ou: "Tinha a sua vaidade positiva. Auto-respeito." (GRUNEWALD, 1997). Cf. tb.: "Vaidoso, introvertido, poupado, desconcertante, gentil, de uma ausente cordialidade, tudo na medida do gênio que sem dúvida o incorporava, e que punha entre ele e a audiência essa exata distância [...]" (AYALA, 1967).

${ }^{23}$ Cf. o conceito de "fala narcísica", em Chauvin (2020).

${ }^{24}$ Cf.: "à chaque fois qu'il [Rosa] mentionne quelqu'um [no "Discurso de Posse na ABL], il le fait pour parler de soi-même" (SILVA e VILAR, 2017); ou: "É evidente que [no prefácio "Pequena Palavra", Rosa] elogia aspectos importantes para o seu próprio fazer poético" (GAMA, 2018, p. 164).
} 
Rosa estava bem doente. Era um esquizoide, segundo o diagnóstico clínico do seu colega da Academia Brasileira de Letras, Peregrino Júnior (DANTAS, 1996, p. 92-93). ${ }^{25}$

\subsection{Geraldo França De Lima}

Na véspera da cerimônia de posse na $A B L$,

Rosa baixou a cabeça. Ficou, como de costume, a pensar. ${ }^{26} \mathrm{Com}$ aquele porte majestoso, empinado como coqueiro, ${ }^{27}$ parecia repelir intimidades ou dava uma impressão desfigurada de sua pessoa. Era, no entanto, o mais humilde dos homens, o mais tímido. (LIMA, 1967)

\subsection{Glauber Rocha}

“[...] Guimarães Rosa, alto meio careca, forte, gravata borboleta, óculos, fala fina, de singularminbiguidade macho/feme, delicado, vermelhão, sensual [...]” (ROCHA, 1978, p. 10. sic).

Com esta primeira e breve descrição, Glauber não propõe um delineamento heroico de Guimarães, tampouco contra-heroico. Produz, em vez disso, uma figura hermafrodita na qual convivem o macho e a fêmea, a fortaleza e a delicadeza. Aponta com isso a um dos núcleos centrais de Grande Sertão: a atração que Riobaldo sente por Diadorim, ainda antes que saiba que Diadorim é na realidade uma mulher. (CAMARA, s/d, p. 7).

\subsection{Murilo Rubião}

[...] no elevador do Itamarary (sic) no Rio de Janeiro estava um senhor de gravata borboleta e quando ele ouviu meu nome apresentado pelo diplomata João Pinheiro Neto ele exclamou, "Murilo Rubião! Que coisa nos encontrar mas (sic) aqui. Gostei tanto do Ex-mágico!” Todo o tempo segurando a minha mão. Ele tinha uma voz um pouco efeminada, e, segurando a minha mão por tanto tempo, eu fiquei ruborizado. Quando saímos do elevador, perguntei para João Pinheiro, "Quem é essa bicha de borboleta?" "É o Guimarães Rosa!" Eu sentei no chão, bati com a mão na cabeça, e disse "Essa não!" (RUBIÃO e LOWE, 1978, p. 32). ${ }^{28}$

\subsection{João Condé}

"Não usa chapéus."29

\footnotetext{
${ }^{25}$ Cf.:"Rosa era um homem com dupla personalidade: uma exterior, reservada, vaidosa e aparentemente fútil, e outra interior, absolutamente genial." (MINDLIN, 1998, p. 10).

${ }^{26}$ Uma postura socrática? Cf., em OCT: "Só Sócrates." (p. 53).

${ }_{27}$ Cf.: "[Rosa] Era imponente, e ao mesmo tempo risonho, solícito na conversa fiada", disse Elio Gaspari em depoimento para Vianna (2019, p. 128).

${ }^{28}$ Entretanto, cf.: "Guimarães Rosa, notório apreciador da beleza feminina” (REBELLO, 2014, p. 184). Ou: "[Chico Alvim] declarou: 'ele é muito delicado no trato, mas é macho pra burro'” (BARBOSA, 2007, p. 27). Ou: "Alguém [JGR] sobre quem não se podia cometer o engano de se duvidar da sua masculinidade" (BARBOSA, 2007, p. 27). ${ }_{29} \mathrm{Na}$ descrição que Condé fez de Rosa para a coluna "Flash", dos "Arquivos Implacáveis" do Correio da manhã, ainda em 1947. Assim como outros casos aqui relatados, não há menção na Internet a esse perfil (outros autores que tiveram seu perfil desenhado por Condé, nos seus "Arquivos Implacáveis", tiveram bem mais sorte), que saiu publicado, pela segunda vez, pouco depois da morte do escritor, em 1967, com a data de 1947.
} 


\section{Um Rosa cor-de-rosa?}

É sabido que o homem Guimarães Rosa era bastante vaidoso (Biografemas de Cony e Savassi Rocha), e não cremos desrespeitar a sua memória trazendo esta sua característica à baila, dado que foi ele mesmo quem escreveu um conto sobre o assunto. ${ }^{30}$ Voltando ao conto, concordamos com Riedel (1964), que enfatiza "a utilidade da morte do Vovô Barão para os netos" viverem o seu amor e escaparem, assim, da tradição da soberbia simbolizada na figura dos chapéus que transitam entre os membros da família. Com o conto OCT, os chapéus deixam sim de transitar, tanto para o reflexivo narrador Leôncio Nestorzinho, como para a cabeça do próprio autor (Biografema de João Condé).

No entanto, parte do silêncio da crítica sobre o conto talvez provenha da espinhosa questão que liga, justamente, vida e obra do autor, desconstruindo uma unidimensional imagem cor-de-rosa de um dos mitos brasileiros mais caros. Acreditamos que existe, em curso, um zelo de manter "limpa" a memória do maior escritor brasileiro do século XX (Biografema de Vilma Guimarães Rosa).

Fazendo parte dessa higienização da figura do autor, nunca, ao que se saiba, relacionou-se a afirmação de Rosa de que Grande sertão: veredas seria sua "autobiografia irracional” (LORENZ, 1994, p. 58) com o fato de que o romance trata de um amor homossexual não-realizado, sendo Riobaldo um autêntico bissexual (Biografemas de Glauber Rocha e de Murilo Rubião):

Eu ria muito quando estudiosos iam estudar essa questão do Rosa - estudos como "O amor em Guimarães Rosa", em que você falava de tudo, menos da homossexualidade. Não dele, Rosa, não é isso o que está em causa, não se trata disso. Eu digo de ele ter abordado exatamente um assunto proustiano: a homossexualidade. Os críticos brasileiros, os brasileiros em geral, são muito hipócritas a esse respeito, não é? Quer dizer, você não pode estudar direito Fernando Pessoa, não pode estudar direito Mário de Andrade, não pode estudar direito Rosa, porque você fala em homossexualidade e parece um escândalo. Mas na verdade é o que se passa. (PIGNATARI, 2014)

Entretanto, reconhecemos, sobretudo, que a prática biografemática nunca envolverá “o retrato acabado mas tão somente o desejo de encontrá-lo, num rosto que será <sempre> etéreo" (COSTA, 2010, p. 108). Assim, o hábito de Rosa de recolher cuidadosamente textos elogiosos sobre sua própria obra (e as críticas negativas, colá-las de ponta-cabeça nos seus famosos cadernos $)^{31}$ é, com certeza, nada mais que demasiado humano: Moacyr Scliar, por exemplo, "satisfeito

\footnotetext{
30 Sobre a vaidade como uma das espécies da Soberba, cf.: "San Juan de la Cruz enumera os sete males que causam mais estragos no espírito do homem. Todos são variantes da soberba: vaidade, vanglória, presunção, jactância, menosprezo, altivez, fatuidade" (MARTINEZ, 2002, p. 60). Por outro lado, é notável que, dentre o variado espectro de termos associados à Soberba em OCT [altivez (p. 37), sobranceiros (38), arrogante (38), soberbissimice (38), prepotente (47), gabava-se (48), orgulhoma (48), desprezando-se (51), ostensão (52), presunção (52), arrogância (52), desdenhava (52), orgulhamento (54), desdém (54), fátuo (55), altivo (57), sobrançaria (57), prepotentíssimo (57), jactância (59), gloriavã (61), arrogante (62), presunção (62)], não comparece, exatamente, a vaidade... Teria esta sido eludida?

31 "[Rosa] Colecionava avidamente não importa que papel impresso no qual aparecia seu nome" (FLUSSER, 2007, p. 140). Cf., sobre o Vovô Barão: "ele se colecionava" (OCT, p. 35). Não sei se o presente ensaio mereceria ser arquivado de ponta-cabeça.
} 
com uma crítica favorável, guardava-a no bolso, retirando de tempos em tempos para reler" (MACEDO, 2016, p. 47).

Ao menos, avaliamos que Rosa não era adepto da "falsa modéstia", conforme carta ao tradutor alemão datada de apenas dois dias após a conclusão do datiloscrito de OCT: "sem falsa modéstia ('Nur die Lumpen sind bescheiden!' ['Só os coitados são modestos'], diz, com certo exagero mas com alguma verdade Schopenhauer) - creio poder crer que podemos alcançar, juntos, notáveis vitórias", escreve a Meyer-Clason, em 23/04/1963 (ROSA, 2003a).

E chegava até mesmo a brincar com o assunto:

Era 1963 [...]. Segundo relato de Aurélio [Buarque de Holanda] a Josué Montello, ao ser apresentado aos jornalistas, o escritor [Rosa] fez um comentário pilhérico. Um deles retrucou, em tom contrariado: “- o senhor é muito engraçado" e Rosa: “- Sim, sou. Mas, engraçado só, não: sou inteligente, e culto, e elegante, e simpático, e bonito." Depois levantou-se e despediu-se, com picardia: “- na entrevista, não se esqueçam de ressaltar minha modéstia." (Josué Montello, Diário do entardecer, 02/07/1975, p. 133, citado a partir de VIANNA, 2019, p. 132)

Todavia, é curioso que Rosa, tendo uma vez afirmado que não leria mais os romances de Machado de Assis, por provirem da "mais desprezível forma do egoísmo: o egoísmo dos introvertidos inteligentes", "sendo uma desoladora dissecação do egoísmo" (CADERNOS, 2006, p. 86), construa, em OCT, um narrador diferente dos narradores habituais de suas obras, pois "pertence à mesma classe alta da personagem que é objeto da narração" (CHIAPPINI, 2002, p. 222), é "herdeiro das elites" [filho de um "capitalista em ócios" (OCT, p. 37)] e, "ao mesmo tempo, se distancia irônica e machadianamente dela" (CHIAPPINI, 2002, p. 226): "com o distanciamento lúcido do humor desestruturante" (RIEDEL, 1974).

Teria Rosa se incomodado tanto com a "dissecação do egoísmo" praticada por Machado (autor do célebre poema "Mosca azul", ${ }^{2}$ desde então emblema do orgulho) que nem o ler queria mais, e, no entanto, utilizado um procedimento machadiano na escritura de OCT, que trata justamente da Soberba?

Continuando a "fricção entre vida e ficção" (MARINHO, 2011, p. 247), podemos enxergar, na enigmática morte do autor (cf. MARINHO, 2012, p. 189; MARINHO e SILVA, 2019b, p. 823; MARINHO e SILVA, 2020, p. 21), o "poder do homem que organiza o ritual da sua própria morte", ${ }^{33}$ conforme assinala Riedel (1974) sobre o Vovô Barão, ecoando o "caixãozinho cor-de-rosa, com enfeites verdes brilhantes" de Nhinhinha (ROSA, 2001, p. 61)? ?4 $^{34}$

\footnotetext{
${ }^{32}$ Cf. a primeira estrofe do poema: "Era uma mosca azul, asas de ouro e granada, / Filha da China ou do Indostão, Que entre as folhas brotou de uma rosa encarnada, / Em certa noite de verão" (ASSIS, 1962, p. 161-162). Cf., sobre o poema e a eleição de Rosa para a ABL, Silva e Vilar (2017, p. 77-78).

${ }^{33}$ Cf.: "Antonio Callado busca extrair do autor [Rosa] uma confissão qualquer que pudesse justificar, por parte do consagrado romancista, tanta diligência para ingresso na Academia; e obtém a humorada resposta: 'O enterro, meu querido, os funerais. Vocês, cariocas, são muito imprevidentes. A academia tem mausoléu e quando a gente morre cuida de tudo'" (MARINHO, 2012, p. 189)

34 Ambos, Rosa e Nhinhinha, são "inábeis" (respectivamente ROSA, 2008, p. 558; ROSA, 2001, p. 59). E Nhinhinha, ainda por cima, é "inábil como uma flor" (ROSA, 2001, p. 59).
} 


\section{Conclusão}

É assim que os biografemas aqui coletados erigem uma imagem cheia de paradoxos, ambígua e ambivalente, que talvez apenas possa ser explicada pela complexa definição que Flusser deu de Rosa: ele "Tinha a humildade da hýbris" (2007, p. 142). ${ }^{35}$

Porém, o que sobra de concreto desta aventura "semiautobiográfica" (RABASSA, 1970, p. 32) são alguns textos que aparentemente foram apagados da instituição acadêmica, e mesmo de toda a Internet: o próprio OCT; o perfil original (de 1947) da coluna "Flash" de João Condé; "O urso e os titãs"; a entrevista de Cony sobre a distribuição dos pecados; e mesmo a entrevista de 2015, que contém um juízo de valor tão peremptório, emitido pelo quase-nonagenário membro da ABL, e de que há, na íntegra, apenas duas entradas, no Google comum (acessado em 19 mar. 2020).

Como conclusão provisória, então, mesmo sabendo que tais indagações não poderão nunca serem respondidas, questionamos uma possível imagem cor-de-rosa do autor legada por sua fortuna crítica, que talvez considere alguns temas como tabus, evitando-os, ${ }^{36}$ como: o próprio conto "Os chapéus transeuntes" (e, por conseguinte, "O urso e os titãs", de Fausto Wolff); o desejo homoafetivo frustrado de Riobaldo, protagonista de uma "autobiografia irracional"; a morte do autor por infarto, três dias após proferir um discurso obsessivamente marcado pelo campo semântico da palavra "coração", e que se encerra com uma sentença sobre a morte ("as pessoas não morrem, ficam encantadas") que havia sido pronunciada pela primeira vez aos dezessete anos, e guardada durante quarenta anos para ser repetida somente nesse momento solene; as incríveis dificuldades relativas a tornar público tudo que pertence ao espólio do autor, a interdição de sua biografia (BARBOSA, 2007), a inexistência, até pouco tempo atrás, de qualquer registro audiovisual seu, homem público, falecido já em 1967; o exagero de Rosa com relação a tudo que dizia respeito à Academia Brasileira de Letras (por que alguém que tinha já em vida a consagração mundial, cogitado até para o Prêmio Nobel, dizia dar tanta importância à $\mathrm{ABL}$ ? E por que adiou a posse por quatro anos, deixando, inclusive, de receber o gordo estipêndio a que têm direito os Imortais, ele que gostava tanto de dinheiro? ${ }^{37} \mathrm{E}$, se dava tanto valor assim à Academia, por que nunca quis publicar Magma, laureado por ela?); a inegável vaidade de Rosa, a qual transparece, por exemplo, nas correspondências com os

\footnotetext{
${ }^{35}$ Ainda que cuidando do problema colocado por Sant'Anna [“[T]emos aqui uma delicada situação. Situação de primazia. Estamos tratando do mais importante dos pecados, do qual decorrem todos os demais, e isso nos coloca em cheque, porque não podemos falar desse pecado com soberba, como se tivéssemos sido privilegiados. Tenho que evitar cair nesse pecado e enfrentar o tema sem soberba." (2001, p. 133)], como não pensar que com a Soberba se passe o mesmo que Julia Kristeva disse da melancolia: "Para aqueles a quem a melancolia devasta, escrever sobre ela só teria sentido se o escrito viesse da melancolia" (1989, p. 11)?

${ }^{36}$ Fica por se fazer, também, a relação do sobrenome do autor ("rosa") significando "ânus", que Houaiss dá como "tabuísmo", precisamente em Minas Gerais. Para alguém tão obcecado com as palavras, especialmente com os nomes próprios, ainda mais o seu próprio nome, como deve ter sido atravessar a vida portando um palavrão como nome, e ainda por cima, tabu? Seria possível ligá-lo ao penico "de hediondo gosto" do Vovô Barão, com seu "olho humano" "arregalado com expressão de espanto" (OCT, 57), pintado no fundo?

37 Cf. VIANNA, 2019.
} 
tradutores. ${ }^{38}$ Nossa hipótese, todavia, é que a escritura de "Os chapéus transeuntes", no primeiro semestre de 1963, marcou uma transformação íntima no âmago de Guimarães Rosa, a qual escritura, como ato de confissão e contrição através dos questionamentos do narrador reflexivo e autoconsciente, ${ }^{39}$ lhe permitiu, ao corajosamente enfrentar seu demônio da Soberba, sair vitorioso do pleito para a vaga da $\mathrm{ABL}$ aberta em 31/03/1963, o que não fora possível na candidatura derrotada de 1957, por estar próxima demais do glorioso ano dionisíaco de $1956 .{ }^{40}$

\section{REFERÊNCIAS}

ANTELO, Raul. A hybris e o híbrido na crítica cultural brasileira. Literatura e sociedade. São Paulo, v. 14, n. 12, p. 128-150. Disponível em: <http://www.revistas.usp.br/ls/article/view/25358>. Acesso em: 08 mai. 2020.

ASSIS, Machado de. Ocidentais. In: Machado de Assis - Obra Completa. Org. : Afrânio Coutinho. Vol. III Poesia, Crônica, Crítica, Miscelânea e Epistolário. Rio de Janeiro: José Aguilar, 1962.

AXOX, Chiara de Oliveira Carvalho Casagrande Ciodarot di. Solve et coagula: dissolvendo Guimarães Rosa e recompondo-o pela ciência e espiritualidade. 2013. 248f. Tese (doutorado) - Pontifícia Universidade Católica do Rio de Janeiro, Departamento de Letras, Rio de Janeiro.

AYALA, Walmir. Guimarães Rosa: o senhor do encantamento. Correio da manhã, Rio de Janeiro, 25 nov. 1967. Disponível em: <http://memoria.bn.br/DocReader/docreader.aspx?bib=089842_07\&pasta=ano\%20 196\&pesq=encantadas $>$. Acesso em 25-03-2020.

AZEVEDO, Luciene. Representação e performance na literatura contemporânea. Aletria, v. 16, jul.-dez. 2007, p. 80-93. Disponível em: <http://www.periodicos.letras.ufmg.br/index.php/aletria/article/view/1407>. Acesso em: 31 mar. 2020.

AZEVEDO, Luciene. Autoficção e literatura contemporânea. Revista brasileira de literatura contemporânea. São Paulo, n.12, 2008. p. 31-49. Disponível em: <http://revista.abralic.org.br/index.php/revista/article/ view/179/182>. Acesso em: 31 mar. 2020.

BARBOSA, Alaor. Sinfonia Minas Gerais: a vida e a literatura de João Guimarães Rosa. LGE, 2007.

\footnotetext{
${ }_{38}$ Embora diga que "Estou, mesmo, gostando, deste jogo [tradução e dúvidas]. E é benéfico, contribuindo para um pouco de humildade. Pois, agora é que vejo como certos leitores têm razão de irritar-se contra mim e invenctivar-me." (JGR, Carta a Bizzarri de 28.X.63, 2003b, p. 51). Mas, ao mesmo tempo, que gozo é esse que ele extrai ao falar tanto sobre a própria obra? [Cf.: Deveríamos considerar "la soberbia subyacente al 'humilde' Guimarães Rosa, que se proyecta en la ficción a través de la antihumildad que supone una tal exhibición de virtuosismo linguístico-literario como el que despliega en esta su narrativa (OCT)" (MARTíNEZ PEREIRO, 2017, p. 345)].

39 Em "O recado do morro", imediatamente após o "velhouco" Gorgulho deixar a comitiva de Pê-Boi, frei Sinfrão "desembolsou o rosário", e disse ao protagonista: "- Você sabe que o lugar aqui está aconselhando, ô Pedro? [...] Pois para fazer arrependimento dos pecados, p'ra se confessar..." (ROSA, 1978 [1956], p. 23). E Pê-Boi, o herói, "restava perturbado, seu pensamento desobedecia", pois por que "havia de ter ameaçado com aquilo, de contrição e confissão? [...] Aquela [sic] hora, nem que quisesse, não podia dar balanço em pecados nenhuns." (ROSA, 1978 [1956], p. 24).

40 Cf.: "Corpo de baile tem no espírito e no bojo qualquer coisa de dionisíaco (contido), de porre amplo, de enfática 'desmesura'." (ROSA, 2003b, p. 125). Também: "A escritura biográfica de Grande sertão: veredas [...] fundamenta-se na hybris" (HOISEL, 2019, p. 11) E: "Ao princípio dionisíaco da hybris, o pensamento grego opõe o princípio apolíneo da sofrosyne: 'conhece-te a ti mesmo'” (HOISEL, 2004, p. 95).
} 
BOROWSKI, Gabriel. Mapeando as veredas da memória: ficção autonarrativa e autoficção na literatura brasileira. Romanica Cracoviensa, n. 4, 2017, p. 235-244. Disponível em: <www.ejournals.eu/Romanica-Cracoviensia>. Acesso em: 29 jan. 2019.

CADERNOS de literatura brasileira: edição especial comemorativa dos 10 anos: João Guimarães Rosa. Instituto Moreira Salles. São Paulo, no 20 e 21, dez. 2006.

CAIRNS, Douglas R. Hybris, dishonour, and thinking big. The Journal of Hellenic Studies, Edinburgh, vol. 116, 1996, p. 1-32. Disponível em: <http://www.jstor.org/stable/631953>. Acesso em: 29 jan. 2019.

CALOBREZI, Edna Tarabori. Morte e alteridade em Estas estórias. São Paulo: Editora da USP, 2001.

CAMACHO, Fernando. Um diálogo com Guimarães Rosa (1966). Disponível em: <http://www.elfikurten. com.br/2016/05/joao-guimaraes-rosa-entrevistado-por.html>. Acesso em: 25 mar. 2020.

CAMARA, Mário. Coisa gritante: o sertão de Glauber entre o corpo e a política. Disponível em: $<$ https://www. academia.edu/6849777/COISA_GRITANTE_O_SERTAO_DE_GLAUBER_ENTRE_O_CORPO_E_A_POLITICA >. Acesso em: 31 mar. 2020.

CAMARGO, Frederico Antônio Camillo. Da montanha de minério ao metal raro: os estudos para a obra de João Guimarães Rosa. Dissertação (mestrado). FFLCH - USP, 2017.

CHAUVIN, Jean Pierre. Fala narcísica. Revista USP, São Paulo, n. 124, p. 69-78, jan. fev. mar. 2020. Disponível em: <http://www.revistas.usp.br/revusp/article/view/167920/160000>. Acesso em: 31 mar. 2020.

CHIAPPINI, Ligia. A vingança da megera cartesiana: notas sobre Estas Estórias. Scripta. Belo Horizonte, vol. 5, n. 10, $1^{\circ}$ sem. 2002. p. 218-233.

CONDÉ, João. Flash. Correio da manhã, Rio de Janeiro, 25 nov. 1967 [1947], Segundo Caderno, p. 4. Disponível em: <http://memoria.bn.br/DocReader/089842_07/87638>. Acesso em: 31 mar. 2020.

CONY, Carlos Heitor. Pecados Capitais. Folha de São Paulo. 15 dez. 1996. Disponível em: <https://www1. folha.uol.com.br/fsp/1996/12/15/opiniao/6.html>. Acessado em 25 mar. 2020.

CONY, Carlos Heitor. [Entrevista]. [Rio de Janeiro?], [200-]. Disponível em: <http://www.machadodeassis. org.br/abl/outros/rachel/pales19.htm>. Acessado em 14 out. 2016 (atualmente indisponível na rede).

CONY, Carlos Heitor. Entrevista a Álvaro Costa e Silva e Paulo Roberto Pereira. Revista da Academia Carioca de Letras. Edição comemorativa dos 450 Anos da cidade de São Sebastião do Rio de Janeiro. Rio de Janeiro: Batel, 2015. p. 341. Disponível em: <https://docplayer.com.br/6818819-Revista-da-academia-carioca-de-letras.html>. Acesso em 14 out. 16.

COSTA, Luciano Bedin da. Biografema como estratégia biográfica: escrever uma vida com Nietzsche, Deleuze, Barthes e Henry Miller. 2010. 183 f. Tese (doutorado) - Universidade Federal do Rio Grande do Sul, Pós-Graduação em Educação, Porto Alegre.

DANTAS, Paulo. Euclides da Cunha e Guimarães Rosa através dos sertões. São Paulo: Massao Ohno, 1996.

DANTAS, Paulo. Sagarana emotiva: cartas de J. Guimarães Rosa. São Paulo: Duas Cidades, 1975.

FARIA, Ernesto. Dicionário escolar latino-português. Rio de Janeiro: FAE, 1991.

FIGUEIREDO, Eurídice. Mulheres ao espelho: autobiografia, ficção, autoficção. Rio de Janeiro: EDUERJ, 2016 
FLUSSER, Vilém. Bodenlos: uma autobiografia filosófica. Rev. técnica Gustavo Bernardo. São Paulo: Annablume, 2007.

GALERA, Daniel. Superando a autoficção. O Globo, 27 mar. 2013. Disponível em: <http://oglobo.globo.com/ cultura/superando-autoficcao-7410285>. Acesso em: 25 mar. 2020.

GAMA, Mônica Fernanda Rodrigues. "Plástico e contraditório rascunho": a autorrepresentação de João Guimarães Rosa. 2013. 332f. Tese (doutorado) - Universidade de São Paulo, Faculdade de Filosofia, Letras e Ciências Humanas, Pós-Graduação em Literatura Brasileira, São Paulo.

GAMA, Mônica. Caminhos da consagração: Guimarães Rosa e o julgamento crítico. O eixo e a roda, Belo Horizonte, v. 27, n. 3, pp. 151-174, 2018. Disponível em: <http://www.periodicos.letras.ufmg.br/index.php/o_ eixo_ea_roda/article/view/13529>. Acesso em: 29 jan. 2019.

GRÜNEWALD, José Lino. O ritmo encantatório de Rosa. Folha de São Paulo, 14 set. 1997. Disponível em: <https://www1.folha.uol.com.br/fsp/mais/fs140923.htm>. Acesso em: 31 mar. 2020.

HEIDEGGER, Martin. Heráclito - A doutrina heraclítica do logos (semestre de verão de 1944). Trad.: Márcia Sá Cavalcante Schuback. RJ: Relume Dumará, 1998.

HIDALGO, Luciana. Autoficção brasileira: influências francesas, indefinições teóricas. Alea. Rio de Janeiro, vol. 15/1, p. 218-231, jan.-jun. 2013. Disponível em: <http://www.scielo.br/pdf/alea/v15n1/a14v15n1.pdf>. Acesso em: 31 mar. 2020.

HOISEL, Evelina. Grande sertão: veredas - genealogias. Légua e meia: revista de literatura e diversidade cultural. Feira de Santana-BA, UEFS, ano 3, n. 2. p. 85-99, 2004. Disponível em: <http://leguaemeia.uefs. br/2/2_86-99grande.pdf>. Acesso em: 31 mar. 2020.

HOISEL, Evelina. A escritura anagramática de Grande sertão: veredas. Línguas \& letras. Cascavel-PR, v. 19, n. 5, p. 8-28, 2019. Disponível em: <http://e-revista.unioeste.br/index.php/linguaseletras/article/view/22095>. Acesso em 31 mar. 2020.

KLINGER, Diana. Escrita de si como performance. Revista brasileira de literatura comparada, n. 12, 2008, p. 11-30. Disponível em: <revista.abralic.org.br/index.php/revista/article/download/178/181>. Acesso em: 29 jan. 2019.

KLINGER, Diana. Escritas de si, escritas do outro: o retorno do autor e a virada etnográfica. $3^{\text {a }}$. ed. Rio de Janeiro: 7Letras, 2012.

KRISTEVA, Julia. Sol negro: depressão e melancolia. Trad. Carlota Gomes. RJ: Rocco, 1989.

LIMA, Geraldo França de. As últimas horas de Guimarães Rosa. Correio da manhã, Rio de Janeiro, 25 nov. 1967. Disponível em: <http://memoria.bn.br/DocReader/docreader.aspx?bib=089842_07\&pasta=ano\%20 196\&pesq=encantadas $>$. Acesso em: 25 mar. 2020.

LÍSIAS, Ricardo. Eu sou normal. Scriptorium. V.1, n.1, p. 84-100, jul.-dez. 2015. Disponível em: <http://revistaseletronicas.pucrs.br/ojs/index.php/scriptorium/article/view/21617>. Acessado em: 25 mar. 2020.

LORENZ, Günter. Diálogo com Guimarães Rosa. In: ROSA, João Guimarães. Ficção completa em dois volumes. Rio de Janeiro: Nova Aguilar, 1994. p. 27-61.

MACEDO, André Barbosa de. As obras de Graciliano Ramos e Guimarães Rosa nos rodapés de Wilson Martins e Franklin de Oliveira. Veredas: revista da Associação Internacional de Lusitanistas. N. 25, p. 32-53, jan.-jun. 2016. 
MARINHO, Marcelo. João Guimarães Rosa, "autobiografia irracional" e crítica literária: veredas da oratura. Letras de hoje. Porto Alegre, v. 47, n. 2, abr.-jun., 2012.p. 186-193. Disponível em: <http://revistaseletronicas. pucrs.br/ojs/index.php/fale/article/view/11315>. Acesso em: 29 jan. 2019.

MARINHO, Marcelo. João Guimarães Rosa, autobiografias e vanguarda: pela viva voz da oratura. Anais do SENAEL, SELIRIS e SINEL. Frederico Westphalen, n. 3, mai. 2011. p. 244-252. Disponível em: $<$ www.fw.uri. br/NewArquivos/pos/publicacao/39.pdf >. Acesso em 29 jan. 2019.

MARINHO, Marcelo e SILVA, David Lopes da. Anastasia e pervivência em João Guimarães Rosa: vita brevis, ars longa. O eixo e a roda. Belo Horizonte, v. 28, n. 1, p. 253-281, 2019a. Disponível em: <http://www.periodicos.letras.ufmg.br/index.php/o_eixo_ea_roda/article/view/13411>. Acesso em: 14 mai. 2020.

MARINHO, Marcelo e SILVA, David Lopes da. "Desenredo", de João Guimarães Rosa: prosoema, metapoesia, necrológio prévio ou "autobiografia irracional"? Remate de males. Campinas-SP, v. 39, n.2, p. 799-829, jul./ dez. 2019b. Disponível em: <https://periodicos.sbu.unicamp.br/ojs/index.php/remate/article/view/8655681>. Acesso em: 14 mai. 2020.

MARINHO, Marcelo e SILVA, David Lopes da. De Ramayana a Sagarana: a "bela morte" em João Guimarães Rosa. Terceira margem, Rio de Janeiro, v. 24, n. 42, p. 8-28, 2020. Disponível em: <https://revistas.ufrj.br/ index.php/tm/article/view/30897/0>. Acesso em: 14 mai. 2020.

MARTÍNEZ PEREIRO, Carlos Paulo. Una transacción de ojos y retrato: la soberbissimice y esta estória de "Os chapéus transeuntes". In: RIVAS HERNÁNDEZ, Ascensión (ed.). João Guimarães Rosa: un exiliado del linguaje común. Salamanca: Ediciones Universidad de Salamanca, 2017. pp. 327-349.

MARTINEZ, Tomás Eloy. O voo da rainha. Trad. Sérgio Molina. Rio de Janeiro: Objetiva, 2002.

MINDLIN, J. Depoimento. Scripta - Literatura. Edição especial do Seminário Internacional Guimarães Rosa. Belo Horizonte, v.2, n.3, $2^{\circ}$ sem. 1998. p. 9-10.

MINDLIN, José. [sem título]. Cadernos de literatura brasileira. Instituto Moreira Salles, n. 20 e 21, 2006, p. 64-65.

NASCIMENTO, Evando. Autoficção como dispositivo: alterficções. Matraga, Rio de Janeiro, vol. 24, n. 42, set.-dez. 2017, p. 611-634. Disponível em: <https://www.e-publicacoes.uerj.br/index.php/matraga/article/ viewFile/31606/23295>. Acesso em: 31 mar. 2020.

OLIVEIRA, Bruno Lima. Autor implícito, Machado personagem. XI Congresso internacional da ABRALIC - Tessituras, Interações, Convergências. São Paulo, 13 a 17 jul. 2008.

PASSOS, Cleusa Rios P. A voz e a letra dos excluídos: notas sobre o feminino em Guimarães Rosa: exclusão e resistência. In: PEREIRA, Mário Eduardo Costa (org.). Leituras da Psicanálise: estéticas da exclusão. Campinas-SP: Mercado de Letras; Associação de Leitura do Brasil, 1998. p. 147-168 (Coleção Leituras no Brasil).

PASSOS, Cleusa Rios P. Guimarães Rosa: do feminino e suas estórias. São Paulo: Hucitec; FAPESP, 2000

PIGNATARI, Décio. Grande sertão: veredas: Décio Pignatari sobre Guimarães Rosa. Disponível em: <https://youtu.be/ODQPGaSWdkg >. Acesso em: 31 mar. 2020.

RABASSA, Gregory. João Guimarães Rosa: The Third Bank of the River. Books Abroad, vol. 44, no. 1, 1970, pp. 30-35. Disponível em: <www.jstor.org/stable/40124042>. Acesso em: 31 mar. 2020. 
RAMOS, Graciliano. Um livro inédito. In: RAMOS, Graciliano. Linhas tortas. 18a. Ed. São Paulo; Rio de Janeiro: Record, 2002, p. 148-149.

REBELLO, Ivana Ferrante. Arquivo secreto: dedicatória e cartas de amor na escrita de Grande sertão: veredas. Letras de hoje, Porto Alegre, v. 49, n. 2, p. 180-189, abr.-jun. 2014.

RIEDEL, Dirce Côrtes. A verdade poética e a essência do pecado. Jornal do Commercio, 02 e 03 mai. 1964. p. 2-3 (Consultado no Instituto de Estudos Brasileiros da Universidade de São Paulo).

RIEDEL, Dirce Côrtes. De chapéu e bengala. Minas Gerais (suplemento literário), 21 dez. 1974.

ROCHA, Glauber. Riverão Suassurana. Rio de Janeiro: Record, 1978.

ROCHA, Luiz Otávio Savassi. João Guimarães Rosa. Belo Horizonte: Imprensa da UFMG, 1981.

ROSA, João Guimarães. Correspondência com seu tradutor alemão Curt Meyer-Clason (1958 - 1967). Trad.: Erlon José Paschoal. Rio de Janeiro: Nova Fronteira; Academia Brasileira de Letras; Belo Horizonte: Ed. da UFMG, 2003a.

ROSA, João Guimarães. Correspondência com seu tradutor italiano Edoardo Bizzarri. 3ª ed. Rio de Janeiro: Nova Fronteira, 2003b.

ROSA, João Guimarães. Os chapéus transeuntes. In: ROSA, João Guimarães. Estas estórias. 2a . ed. Rio de Janeiro: José Olympio, 1976 [1969]. p. 34-65.

ROSA, João Guimarães. Os chapéus transeuntes. In: SILVEIRA, Ênio (org.). Os sete pecados capitais. Capa de Eugênio Hirsch. Rio de Janeiro: Civilização Brasileira, 1964. p. 1-36.

ROSA, João Guimarães. A menina de lá. In: ROSA, João Guimarães. Primeiras estórias. Rio de Janeiro; Nova Fronteira, 2001 (edição digital).

ROSA, João Guimarães. O verbo \& o logos. In: ROSA, Vilma Guimarães. Relembramentos: João Guimarães Rosa, meu pai. 3a . ed., rev., ampl. Rio de Janeiro: Nova Fronteira, 2008. p. 555-586.

ROSA, Vilma Guimarães. Relembramentos: João Guimarães Rosa, meu pai. $3^{\text {a }}$. ed., rev., ampl. Rio de Janeiro: Nova Fronteira, 2008.

ROSENFIELD, Kathrin. Os Descamínhos do Demo: tradição e ruptura em Grande Sertão: Veredas. Rio de Janeiro: Imago; São Paulo: EDUSP, 1993.

RUBIÃO, Murilo; LOWE, Elizabeth. Entrevista com Murilo Rubião. Chasqui, vol. 7, n. 3, maio 1978, p. 24-33. Disponível em: <https://www.jstor.org/stable/29739437>. Acessado em: 28 mar. 2020.

SANT'ANNA, Affonso Romano de. Orgulho. In: YUNES, Eliana; BINGEMER, Maria Clara Luchetti. Pecados. Rio de Janeiro: Ed. PUC-Rio; São Paulo: Loyola, 2001. p. 132-139.

SARAMAGO, José. O Evangelho segundo Jesus Cristo: romance. São Paulo: Companhia das Letras, 2005.

SEGATTO, José Antônio e LEONEL, Maria Célia. Graciliano Ramos: configurações autobiográficas. Itinerários. Araraquara-SP, n. 40, p. 75-95, jan.-jun. 2015. Disponível em: <https://periodicos.fclar.unesp.br/itinerarios/article/view/8167>. Acesso em: 31 mar. 2020.

SILVA, David Lopes da. Enciclopédia jagunça. Maceió: EDUFAL, 2011. 
SILVA, David Lopes da; VILAR, Fernanda. Guimarães Rosa "Ad Immortalitatem": la mort et l'immortalité dans "Le verbe \& le logos". Nonada, Porto Alegre, v. 2, n. 29, 2017, p. 76-88.

SILVA, David Lopes da. Tirando o chapéu: o capítulo de Guimarães Rosa para o livro coletivo Os sete pecados capitais (1964). Cenários, Porto Alegre, v. 2, n. 16, 2017/2018, p. 242-262.

SOUZA, Eneida Maria de. Crítica biográfica - ainda. Cadernos de estudos culturais, Campo Grande-MS, v. 1, pp. 59-66, jul./dez. 2010. Disponível em: <http://seer.ufms.br/index.php/cadec/article/view/4488>. Acesso em: 29 jan. 2019.

SOUZA, Eneida Maria de. Notas sobre a crítica biográfica. In: SOUZA, Eneida Maria de. Crítica Cult. Belo Horizonte: Editora da UFMG, 2002. p. 111-120.

VIANNA, Andréa Ramos Jubé. O jornalismo em Guimarães Rosa: aproximações. Dissertação (mestrado). Brasília, 2019.

WOLFF, Fausto. O urso e os titãs. In: RESENDE, Otto Lara [et al.]. Os sete pecados capitais. Rio de Janeiro: Bertrand Brasil, 2000 [1997]. p. 249-270. 